\title{
Variation and possible function of egg sac coloration in spiders
}

Gilbert Barrantes $^{1}$, Luis Sandoval ${ }^{1,2}$, Catalina Sánchez-Quirós ${ }^{1}$, Pierre-Paul Bitton ${ }^{2}$ and Stéphanie M. Doucet ${ }^{2}$ : ${ }^{1} E$ scuela de Biología, Universidad de Costa Rica, San Pedro, San José, Costa Rica ZC-2060. E-mail: gilbert.barrantes@gmail.com; ${ }^{2}$ Department of Biological Sciences, 401 Sunset Avenue, Biology Building, University of Windsor, Windsor, Ontario, Canada N9B 3P4

\begin{abstract}
Coloration of the egg sacs of spiders varies widely to the human eye, both across and within taxonomic groups. These differences in coloration are expected with differences in the biology and ecology of different species. Here we measure the spectral properties of the egg sacs of 15 species in six families. Ultraviolet chroma, red chroma, and particularly overall brightness vary widely across and within taxonomic groups. We discuss the spectral properties of the silk of the egg sacs in the context of the physical characteristics of the silk, the reflective properties of the background, the environmental illumination, and the natural history and behavior of the spider species. In most cases, the spectral characteristics of the egg sacs seem to reduce their conspicuousness against the background and in those cases in which the coloration does not reduce the contrast in relation to the background, the low environmental light available may help to camouflage the egg sacs.
\end{abstract}

Keywords: ancestral state, brightness, camouflage, conspicuousness, predator avoidance, red chroma, spectral properties, UV chroma

The different characteristics of egg sacs in spiders are thought to have evolved to protect the female's reproductive investment in several ways (Gertsch 1949). For instance, the multiple layers of silk of varying consistency in egg sacs create and maintain an appropriate internal environment for embryo development (Hieber 1985, 1992a), and they also serve as a barrier to prevent some parasites and predators from reaching the eggs and embryos (Austin 1985; Hieber 1992a,b). Other features, such as long egg sac pedicels and webs built exclusively to maintain the egg sac, further reduce access to the eggs by parasites and predators (Hieber 1992b).

Spider maternal behavior also aids in reducing parasitism and predation. For example, females of many species (e.g., Tengella radiata and theridiids) protect the egg sacs, especially during the first days after producing them (Bristowe 1958; Barrantes 2008), when eggs are likely more susceptible to parasitoids. Some spiders (e.g., lycosids and pisaurids), attach the egg sacs to their chelicerae or spinnerets until the spiderlings emerge (Foelix 2011). Other spiders camouflage the egg sacs with silk stabilimenta (Herberstein et al. 2000; Eberhard 2003), pieces of debris (Barrantes 2007), or wrap egg sacs in a leaf (Moya et al., 2010) to protect eggs against parasites and predators.

The coloration of egg sacs varies widely, but there is no information on the pigments responsible for the differences in color, or on their roles in camouflage. Effectiveness in camouflage depends on color, shape, and especially the contrast created by the external layer of the egg sac against the visual background (Craig 2003). The color of the egg sac may not affect protection of some spiders that produce and maintain their egg sacs deep inside burrows or silk tunnels. By contrast, in species that construct and maintain egg sacs in more exposed places, the coloration of the external layer may reduce conspicuousness and provide additional camouflage (e.g., many Theridiidae, Nielsen 1932). Two possible questions to address in relation to the spectral properties of the egg sacs are the following. 1) Does coloration of egg sacs relate to their level of exposure? 2) Is the color of the egg sac associated with the spider's taxonomic (phylogenetic) group?
With few exceptions, the web silk of most spiders is unpigmented (Craig et al. 1994; Craig 2003). Nephila clavipes is one of the few species that adds yellow pigment to its silk web (Craig et al. 1996), although the origin of this pigment is unknown. There is a subtle variation in the color of web silk among webs of $N$. clavipes, with more intense yellow correlating with greater light in the environment in which the spider constructs its web (Craig et al. 1996). On the other hand, the color of the silk used by spiders to construct the external layer of their egg sacs varies widely, at least to the human eye, among species within a given family and among families. In this study we objectively quantify the colors of the silk cocoon from 15 species of spiders in six families, and discuss their potential ecological roles.

\section{METHODS}

We photographed and measured the reflectance of fieldcollected egg sacs of 15 spider species (Table 1) deposited in the collection of the Museo de Zoología, Universidad de Costa Rica, San José, Costa Rica in 2012. We measured from one to five egg sacs per species according to their availability in the collection (Table 2). All egg sacs were collected after the spiderlings emerged, and were kept in dry vials in the dark until measurements were conducted.

We photographed the egg sacs using a Nikon Coolpix 4500 camera attached to a dissecting microscope in order to show the variation in coloration of the egg sacs as perceived by the human eye. We collected several images of each spider egg sac under different light conditions and then selected the image that best matched the color of the egg sac as perceived by two observers (G. Barrantes and C. Sánchez-Quirós) to display in Fig. 1.

To obtain silk reflectance measurements, we used an Ocean Optics USB 2000 spectrometer and a PX-2 flash light source (Ocean Optics, Dunedin, Florida) connected to a bifurcated probe (Ocean Optics R400-7-SR). Such a setup allowed us to obtain all measurements at normal incidence to the reflective surface. We kept the reflectance probe at a fixed distance of 
Table 1.- Characteristics of the habitat and behavior of 15 Costa Rican spider species.

\begin{tabular}{|c|c|}
\hline Family/Species & Egg sac background \\
\hline \multicolumn{2}{|l|}{ Filistatidae } \\
\hline Kukulcania hibernalis (Hentz 1842) & $\begin{array}{l}\text { This synanthropic species constructs its web in dark places and retains the egg sacs within a dense } \\
\text { tunnel retreat constructed of silk. }\end{array}$ \\
\hline \multicolumn{2}{|l|}{ Oxyopidae } \\
\hline Peucetia viridans (Hentz 1832) & $\begin{array}{l}\text { Constructs its egg sacs under leaves of herbs and bushes between } 0.5 \text { to } 1.7 \mathrm{~m} \text { above the ground in } \\
\text { very exposed locations of early secondary vegetation and forest edges. }\end{array}$ \\
\hline \multicolumn{2}{|l|}{ Uloboridae } \\
\hline Zosis geniculata (Olivier 1789) & Attaches the egg sacs to its web, which is constructed in dark locations near the forest floor or in buildings. \\
\hline \multicolumn{2}{|l|}{ Theridiosomatidae } \\
\hline Wendilgarda sp. Keyserling 1886 & $\begin{array}{l}\text { Constructs its egg sac attached by a silk pedicel of approximately } 2 \mathrm{~cm} \text { to leaves or twigs between } \\
0.5 \text { to } 1.5 \mathrm{~m} \text { above the ground, near streams in mature forests. }\end{array}$ \\
\hline \multicolumn{2}{|l|}{ Theridiidae } \\
\hline L. geometricus C. L. Koch 1841 & $\begin{array}{l}\text { Egg sac constructed inside dense silk retreat deep inside web, usually outside buildings, less often } \\
\text { inside. }\end{array}$ \\
\hline L. mirabilis (Holmberg 1876) & $\begin{array}{l}\text { Constructs its web between rocks (outcrop of large rocks) near the ground ( } 5 \text { to } 10 \mathrm{~cm} \text { above the } \\
\text { ground), egg sac protected underneath rocks. }\end{array}$ \\
\hline Steatoda grossa (C. L. Koch 1838) & $\begin{array}{l}\text { Constructs its web under stones in dark places of rain forests and under furniture inside buildings, } \\
\text { egg sac attached to the upper sheet in the web. }\end{array}$ \\
\hline Anelosimus studiosus (Hentz 1850) & $\begin{array}{l}\text { Builds its web in branches, twigs and leaves of bushes in open areas,egg sac constructed inside the } \\
\text { silk tunnel retreat of the web. }\end{array}$ \\
\hline A. pacificus Levi 1956 & Builds its webs on leaves at tips of twigs of trees in open areas, egg sac built between two leaves. \\
\hline Tidarren sisyphoides (Walckenaer 1841) & $\begin{array}{l}\text { Builds its web on bushes in open areas, egg sac retained inside retreats constructed of plant debris, } \\
\text { usually pieces of leaves. T. sisyphoides and } P \text {. tesselata construct their webs on bushes in open } \\
\text { areas, while } P \text {. tepidariorum builds its web outside buildings. }\end{array}$ \\
\hline
\end{tabular}

$5 \mathrm{~mm}$ from the egg sacs during the measurements, using a rubber probe holder. This rubber holder also excluded the external light from the reflectance probe. For each egg sac, we measured the reflectance properties at five different haphazardly selected regions. Reflectance measurements were made relative to that of a diffuse pure white standard (WS-1 Ocean Optics). Our reflectance analyses were restricted to wavelengths from 300 to $700 \mathrm{~nm}$, a range that includes ultraviolet (UV) through red colors.

Spectral curves for each egg sac were visually inspected by one of us who had not previously seen the egg sacs or images of them (P.-P. Bitton), and any measurement that deviated strongly from the others was removed from further analyses. We did this, for example, when one spectral curve was clearly different in shape or overall reflectance from the remaining four repeated measures. Differences in measurements most likely occurred when the probe was not placed directly against the surface of the egg sac when collecting data. We took the average of the remaining curves and measured color variables in the consolidated data set. For every egg sac measured, we determined 1) the brightness as the average reflectance over the 300-700nm range,

$$
\sum_{\lambda 300}^{\lambda 700} R_{i} / n
$$

where $R_{i}$ is the percentage reflectance at the ith wavelength $\left(\lambda_{i}\right)$ and $n$ is the number of wavelength intervals), 2) the ultraviolet (UV) chroma,

$$
\sum_{\lambda 300}^{\lambda 400} R_{i} / \sum_{\lambda 300}^{\lambda 700} R_{i}
$$

and 3) the red chroma,

$$
\sum_{\lambda 600}^{\lambda 700} R_{i} / \sum_{\lambda 300}^{\lambda 700} R_{i}
$$

All measures are described in more detail in Montgomerie (2006). We elected to describe the spectral reflectance of the egg sacs with UV and red chroma because most of the variation among species occurred in these regions. We did not determine the hue for any of the egg sacs measured because all spectral curves peaked near $300 \mathrm{~nm}$ or $700 \mathrm{~nm}$, rendering this common color descriptor uninformative. The spectral data were manipulated and analyzed using the R package "pavo" 
Table 2.- Silk egg sac color characteristics for 15 species of Costa Rican spiders. Brightness is the average reflectance relative to a white standard (see methods) over the 300-700nm range. Ultraviolet (UV) chroma and red chroma are the contribution of the 300-400nm range and $600-700 \mathrm{~nm}$ range, respectively, to the total brightness. Values represent means \pm SD obtained from $n$ samples.

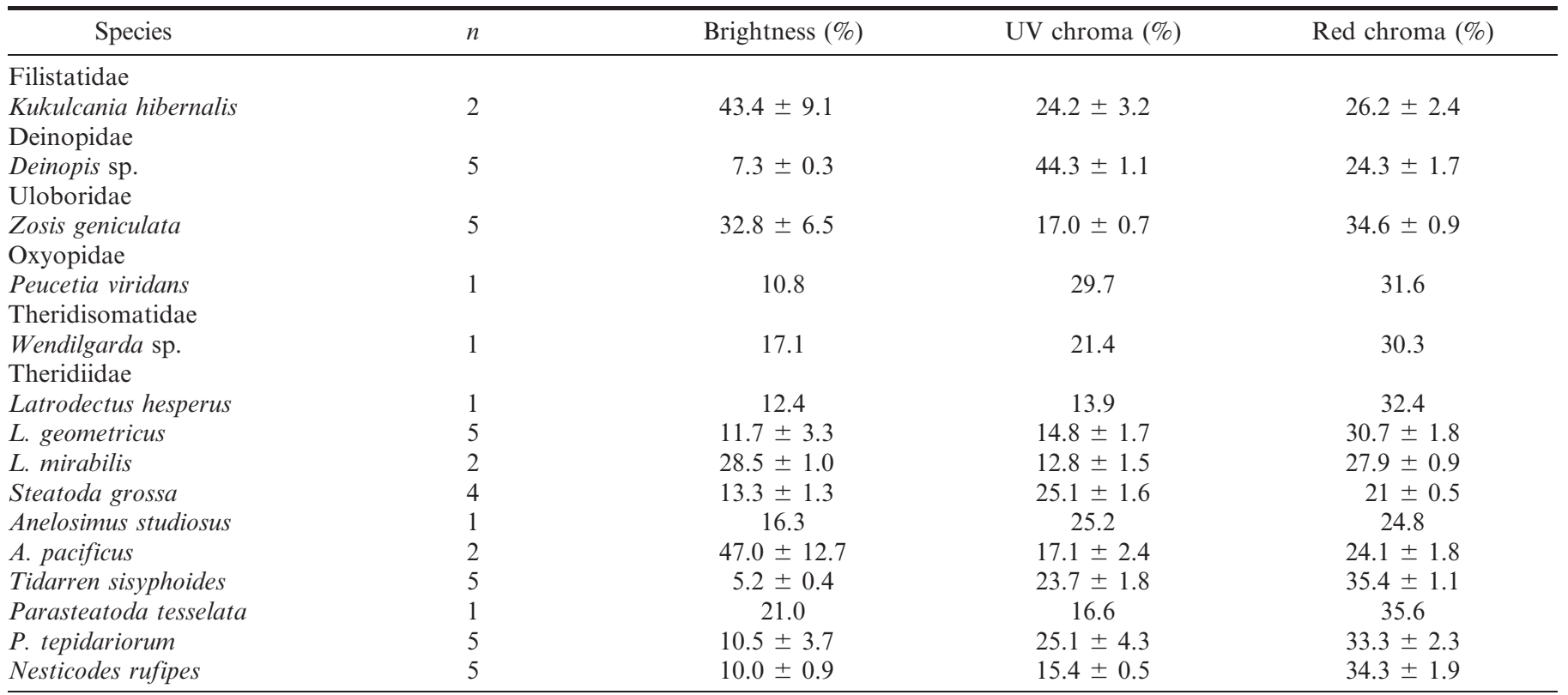

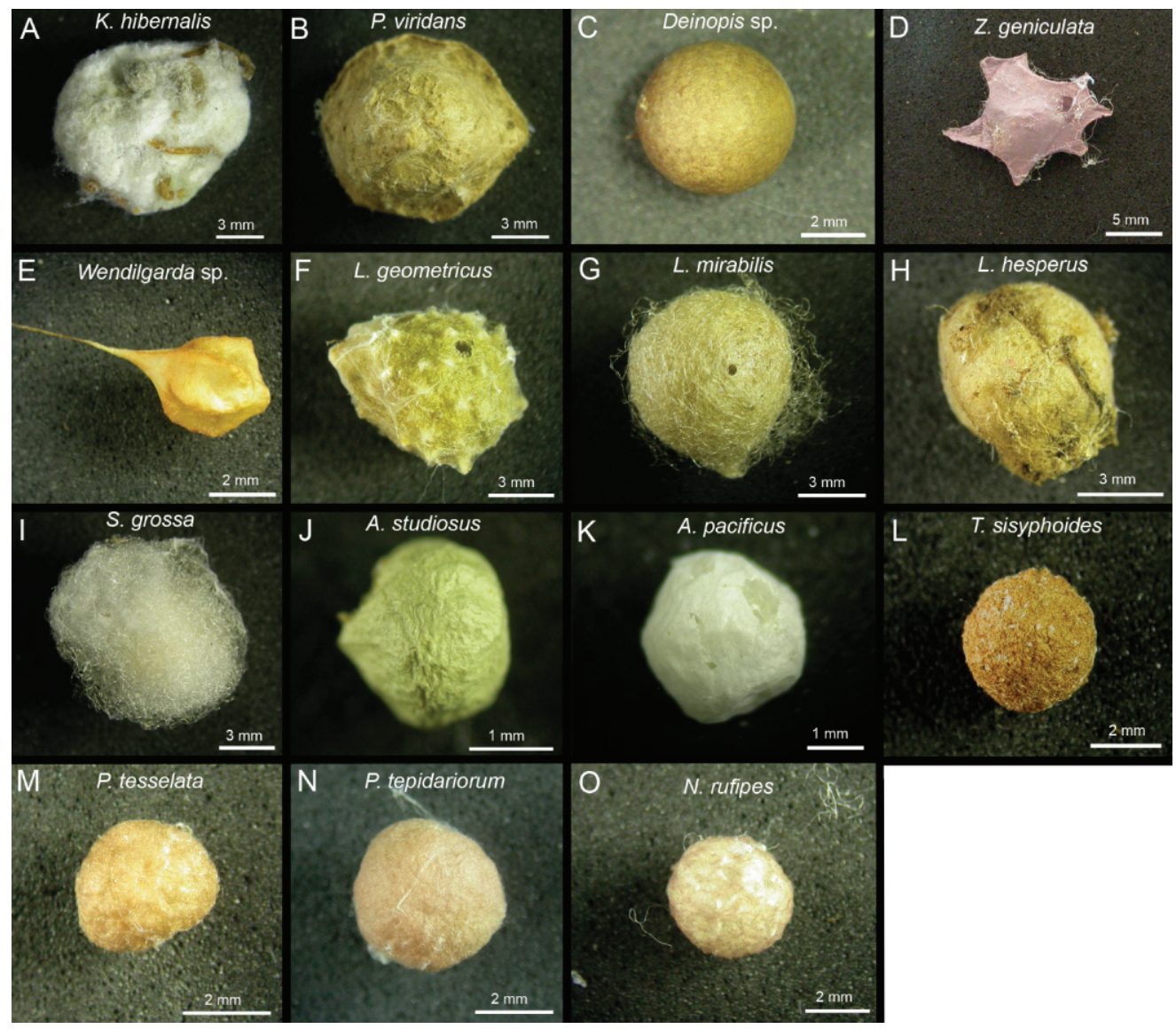

Figure 1.-Egg sacs of 15 species of Costa Rican spiders. 

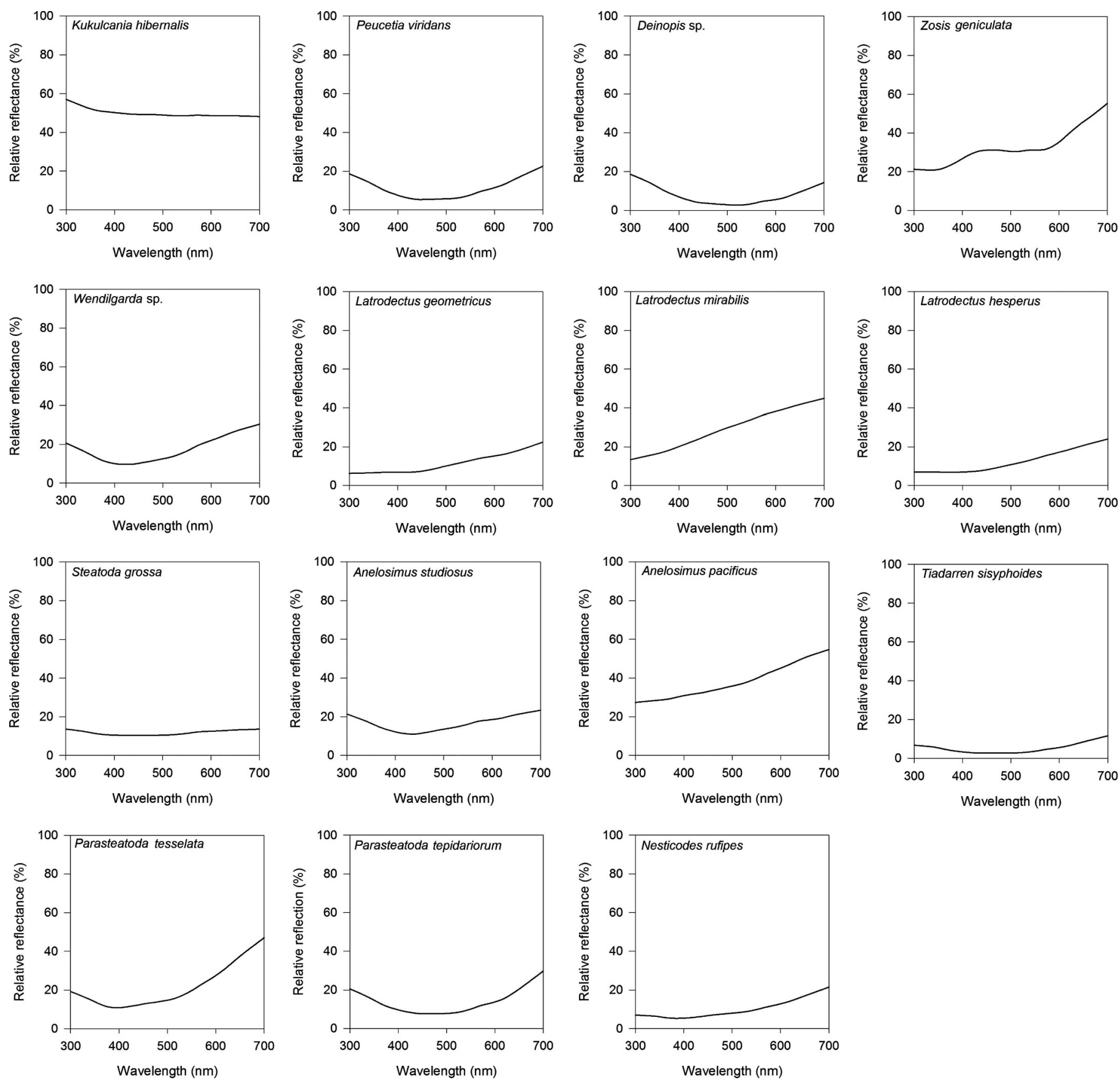

Figure 2.-Mean spectral curves of silk egg sacs for 15 species of Costa Rican spiders. Percentage reflectance is relative to a pure diffuse white standard (see methods).

(Maia et al. 2013). Authorities for the scientific names of all 15 species in this study are listed in Table 1.

\section{RESULTS}

The silks of the spider egg sacs differed extensively in their brightness $[($ mean $=19.1 \% \pm \mathrm{SD}=13.0 \%)$, UV chroma $(21.8 \% \pm 8.1 \%)$ and red chroma $(29.7 \% \pm 4.7 \%)$; Table 2]. Within the human visible spectrum, the color of the egg sacs ranged from almost black (Tidarren sisyphoides: brightness $=$ $5.2 \%$ ), to pale gray (Kukulcania hibernalis: brightness $=$
43.4\%), with most egg sacs appearing brown (Fig. 1). In 10 of the 15 species, brightness (\%) increased with wavelength (nm) (e.g., Latrodectus spp.: Fig. 2). Several of the egg sacs that appear brown to the human eye had relatively high UV chroma (e.g., Peucetia viridans and Deinopis sp.); species that are sensitive to UV wavelengths would likely be able to distinguish between brown egg sacs with low and high UV chroma. In Deinopis sp., the UV wavelengths contributed a very large portion of the overall brightness (UV chroma = $44.3 \%$ ) and would appear more "UV" than red to UV- 
sensitive species (red chroma $=24.3 \%$ ). In contrast, silk of the egg sacs of the Uloboridae (e.g., Zosis geniculate), the sister family of Deinopidae, had a low UV reflectance, but high reflectance toward the red (Fig. 2).

Within the Theridiidae, silk spectral properties were generally the same across the three Latrodectus species, the two Parasteatoda species and Nesticodes rufipes (Table 2). The brightness of Steatoda grossa was similar to the previous species but with a relatively high UV chroma, while Tidarren sisyphoides had a very low brightness (brightness $=5.2 \%$ ) and a very high value of red chroma $(35.4 \%)$. The two species of Anelosimus were very different from each other (Fig. 2). Anelosimus studiosus was relatively dark (brightness $=16.3 \%$ ) and had very high UV chroma (25.2\%), while A. pacificus was much brighter (brightness $=47 \%$ ) with a relatively low UV chroma $(17.1 \%)$.

\section{DISCUSSION}

In this first study of the spectral characteristics of egg sac silk, we show extensive variation among species in their brightness and chroma. Of particular interest, much variation was found in reflectance in the UV range, a characteristic that is not detectable by the human eye. The silk of the egg sacs of many spiders had a high reflectance toward the red range, giving them a brownish appearance, a feature that probably evolved to reduce the conspicuousness of the egg sacs. Conspicuousness could be reduced if the colored silk of egg sacs reflects wavelengths similar to those reflected by the background, as apparently occurs with the pigmented silk of Nephila clavipes webs (Craig et al. 1996). In addition, the low intensity of light in some environments (Endler 1993) allows red-brownish egg sacs to blend with the surroundings more readily than uncolored egg sacs. Both of these hypotheses remain to be tested.

High reflectance in the silk of webs in the UV range is apparently an ancestral characteristic of spiders (Craig et al. 1994; Bond \& Opell 1999). Silk of webs in the suborder Mygalomorphae, as well as the sticky cribellate silk of basal Araneomorphae and Deinopoidea (Deinopidae and Uloboridae) have high UV reflectance, while the sticky silk of Araneoidea species have a flat or low UV reflectance (Craig et al. 1994). These differences in UV reflectance have been correlated with the ambient light conditions where spiders of these groups build their webs (Bond \& Opell 1999; Craig 2003). Spiders whose silk web has high UV reflectance construct their webs in dim environments (Craig et al. 1994; Bond \& Opell 1999; Craig 2003), while webs with low UV reflectance constructed in light environments are a shared derived character for Araneoidea (Bond \& Opell 1999). However, many species in Araneoidea also build webs in dark environments (e.g., Nesticus in Gertsch 1949 and Spilasma GB unpublished data) and the silk reflectance properties of these species remains unexplored.

The UV reflectance of egg sacs does not always match that of the silk webs of the same spider groups. For instance, UV reflectance is high in the silk web and egg sacs of Kukulcania hibernalis (Filistatidae) and Deinopis sp. (Deinopidae) (Craig et al. 1994; Bond \& Opell 1999), and in the egg sacs of Peucetia viridans (Oxiopidae). However, in contrast to the silk web of uloborids (Craig et al. 1994), the UV reflectance in the silk of egg sacs of Zosis geniculata (Uloboridae) is low. In addition to high UV reflectance in the silk of egg sacs of $P$. viridans and Deinopis, their silk also has a high reflectance toward the red, similar to the egg sacs of Z. geniculata. The UV reflectance in the silk of egg sacs of these species may be an ancestral trait, similar to the high UV reflectance in their silk web (Bond \& Opell 1999; Craig 2003), although to examine the evolution of reflectance on the silk of the outer wall of egg sacs would only be possible with more extensive and comparable data (aciniform silk). Yet the high red reflectance of egg sacs has presumably evolved within these families to reduce the visual contrast of the egg sacs against the background, as they appear to blend with surrounding structures of similar coloration. For instance, $P$. viridans maintain their egg sacs under leaves of grasses and bushes in forest edges and patches of secondary vegetation where dead leaves with similar color to the egg sacs (Fig. 1B) are abundant (G. Barrantes unpublished data). Deinopis sp. live in dim habitats, and their egg sacs hang near dead twigs and vines that to the human eye match the coloration of their egg sacs. Similarly, Uloboridae (e.g., Z. geniculata) inhabit dim sites (Craig et al. 1994; Bond \& Opell 1999) and the color of their egg sacs vary from yellow to red-yellow to brown, to purple, to grayish (Opell 1989, GB unpublished data), probably reducing visual contrast with the background.

We included two families in the clade Araneoidea in this study: Theridiosomatidae (Wendilgarda sp.) and Theridiidae (10 species). The reflectance of the silk of the egg sacs of Wendilgarda is relatively high in the UV and red, similar to that of Deinopis and P. viridans. All theridiosomatids inhabit dense forests. They construct their webs and, in most species, also their egg sacs near the forest floor (Coddington 1986), the darkest stratum in the forest. There are some exceptions; for instance, Wendilgarda construct their webs above the surface of streams, and their egg sacs are hung near the end of twigs and leaves of bushes at about $1 \mathrm{~m}$ above the ground and near streams (Coddington 1986; Eberhard 2001; G. Barrantes unpublished data). Thus the light-brown egg sacs of Wendilgarda are in brighter environments and may be more exposed than those of other genera of Theridiosomatidae, which retain the egg sacs on the web, or hang them on the dense vegetation of understory forests (Coddington 1986). The coloration of the egg sacs of Wendilgarda possibly reduces their conspicuousness, since plant debris (dead leaves and twigs) with similar coloration hangs abundantly on understory plants.

Within the family Theridiidae, the spectral properties of egg sac silk vary widely across species. The pattern of reflectance of the three Latrodectus species is very similar, particularly $L$. geometricus and L. hesperus. In all three species the silk of egg sacs has a high reflectance toward the red. However, the reflectance of the silk of the egg sacs of $S$. grossa, the sister genus of Latrodectus (Agnarsson 2004), is not saturated in any of its range, appearing to the human eye as white (Figs. $1 \& 2$ ). Steatoda grossa construct their webs under stones in rain forests (Levi 1962) or in dark locations inside buildings (Aisenberg et al. 2011), while all Latrodectus species construct their webs and egg sacs in protected but bright environments (though L. geometricus often build their webs and egg sacs inside buildings). The spectral properties of the egg sacs of the two species of the genus Anelosimus (A. studiosus and $A$. 
pacificus) differ markedly. The silk of the egg sac of $A$. studiosus, which is retained inside the silk tunnel web, is relatively dark with similar UV and red reflectance, while egg sacs of $A$. pacificus, in which the adult female positions the egg sac between two live leaves (Agnarsson et al. 2006), are brighter and have high red reflectance. The other theridiids inhabit bright environments and retain their egg sacs, the silk of which has relatively high red reflectance, within retreats constructed with plant debris (e.g., pieces of dead leaves: Triana et al. 2012). Retaining brown-reddish egg sacs inside close retreats constructed with material with similar coloration (to the human eye) likely reduces their conspicuousness.

The color (wavelengths) reflected by the silk of the egg sacs of spiders has likely evolved to reduce their contrast against their background, thus making their detection more difficult for parasitoids and predators. However, our research provides only an understanding of the spectral properties of egg sacs from a human perspective, but does not indicate how egg sacs are perceived by other animals (e.g., predators and parasitoids). At least two other aspects, the ambient light available for reflection and the nature of the background, also affect the perception of the color and thus the conspicuousness of an object (e.g., egg sac: Théry 2006), independent of the color vision of predators and/or parasitoids. Hence, even when egg sacs have, for instance, high UV reflectance, they could be difficult to detect in low light environments even for those animals capable of seeing UV light. This is the case for $K$. hibernalis whose webs are built in dark locations and the egg sac retained inside a dense silk tunnel, and also for Deinopis sp. that construct and leave the egg sacs "unprotected" in the undergrowth of either dense or relatively clear forests (Table 1). Zosis geniculata maintains the egg sacs attached to its web until the emergence of the spiderlings, and the silk of the egg sacs has a low UV reflectance, in contrast to web silk of the family (Uloboridae) (Craig et al. 1994; Bond \& Opell 1998). This spider inhabits dark environments where webs may be inconspicuous despite high UV reflectance, and the low UV reflectance of its egg sacs likely further reduces conspicuousness. In environments with considerable ambient light, the brightness of the egg sac silk may also reduce its conspicuousness. For instance, A. pacificus builds its web and egg sacs in bright, open environments (Agnarsson et al. 2006); thus, the high brightness and low UV reflectance of the egg sacs may reduce its contrast and conspicuousness in open, bright environments. Other theridiids that inhabit bright environments produce egg sac silk with low UV reflectance and reduce the contrast and conspicuousness of their egg sacs by retaining them inside retreats that to the human eye resemble the egg sacs in coloration. Though our data are insufficient to test these hypotheses, they suggest that evolution of coloration in egg sacs of spiders is affected by several aspects of their ecology: the physical properties of the silk that each spider produces, environmental light, and the behavior and natural history of each spider species.

\section{ACKNOWLEDGMENTS}

We thank William Eberhard and two anonymous reviewers for their comments and suggestions on a previous version of this manuscript. This investigation was partially supported by the Vicerrectoría de Investigación, Universidad de Costa Rica
(G. Barrantes), the Natural Sciences and Engineering Research Council of Canada (P.-P. Britton, S.M. Doucet), the Ministerio de Ciencia y Tecnología and the Consejo Nacional para Investigaciones Científicas y Tecnológicas of Costa Rica and the Government of Ontario of Canada (L. Sandoval).

\section{LITERATURE CITED}

Agnarsson, I. 2004. Morphological phylogeny of cobweb spiders and their relatives (Araneae, Araneoidea, Theridiidae). Zoological Journal of Linnean Society 141:447-626.

Agnarsson, I., G. Barrantes \& L.J. May-Collado. 2006. Notes on the biology of Anelosimus pacificus Levi, 1963 (Theridiidae, Araneae) evidence for an evolutionary reversal to a less social state. Journal of Natural History 40:2681-2687.

Aisenberg, A., C. Toscano-Gadea \& S. Ghione. 2011. Guía de arácnidos del Uruguay. Editorial de la Fuga, Montevideo, Uruguay.

Austin, A.D. 1985. The function of spider egg sacs in relation to parasitoids and predators, with special reference to the Australian fauna. Journal of Natural History 19:359-376.

Barrantes, G. 2007. Camouflage in webs of Helvibis longicauda (Araneae: Theridiidae). Bulletin of the British Arachnological Society 14:59-60.

Barrantes, G. 2008. Courtship behavior and copulation in Tengella radiata (Araneae, Tengellidae). Journal of Arachnology 36:606-608.

Bond, J.E. \& B.D. Opell. 1999. Testing adaptive radiation and key innovation hypotheses in spiders. Evolution 52:403-414.

Bristowe, W.S. 1958. The World of Spiders. Collins, London.

Coddington, J.A. 1986. The genera of the spider family Theridiosomatidae. Smithsonian Contributions to Zoology 422:1-96.

Craig, C.L. 2003. Spider Webs and Silk. Tracing Evolution from Molecules to Genes to Phenotypes. Oxford University Press, New York.

Craig, C.L., G.D. Bernard \& J.A. Coddington. 1994. Evolutionary shifts in the spectral properties of spider silks. Evolution 48:287-296.

Craig, C.L., R.S. Weber \& G.D. Bernard. 1996. Evolution of predator prey systems: spider foraging plasticity in response to the visual ecology of prey. American Naturalist 147:205-229.

Eberhard, W.G. 2001. Trolling for water striders: active searching for prey and the evolution of reduced webs in the spider Wendilgarda sp. (Araneae, Theridiosomatidae). Journal of Natural History 35:229-251.

Eberhard, W.G. 2003. Substitution of silk stabilimenta for egg sacs by Allocyclosa bifurca (Araneae: Araneidae) suggests that silk stabilimenta function as camouflage devices. Behaviour 140:847-868.

Endler, J.A. 1993. The color of light in forests and its implications. Ecological Monographs 63:1-27.

Foelix, R. 2011. Biology of Spiders. Third edition. Oxford University Press, New York.

Gertch, W.J. 1949. American Spiders. Van Nostrand, Princeton, New Jersey.

Herberstein, M.E., C.L. Craig, J.A. Coddington \& M.A. Elgar. 2000. The functional significance of silk decorations of orb-web spiders: a critical review of the empirical evidence. Biological Reviews 75:649-669.

Hieber, C.S. 1985. The "insulation" layer in the cocoons of Argipoe aurantia (Araneidae: Araneae). Journal of Thermal Biology 10:171-175.

Hieber, C.S. 1992a. The role of spider cocoons in controlling desiccation. Oecologia 89:442-448.

Hieber, C.S. 1992b. Spider cocoons and their suspension systems as barriers to generalist and specialist predators. Oecologia 91:530-535.

Levi, H.W. 1962. The spider genera Steatoda and Enoplognatha in America (Araneae, Theridiidae). Psyche 69:11-36. 
Maia, R., C.M. Eliason, P.-P. Bitton, S.M. Doucet \& M.D. Shawkey. 2013. pavo: an $\mathrm{R}$ package for the analysis, visualization and organization of spectral data. Methods in Ecology and Evolution: DOI: $10.1111 / 2041-210 X .12069$

Montgomerie, R. 2006. Analyzing colors. Pp. 90-147. In Bird Coloration, Mechanisms and Measurements. (G.E. Hill \& K.J. McGraw, eds.). Harvard University Press, Cambridge, Massachusetts.

Moya, J., R. Quesada, G. Barrantes, W.G. Eberhard, I. Escalante, C. Esquivel, A. Rojas, E. Triana \& A. Arias. 2010. Egg sac construction in folded dead leaves by Pozonia nigroventris and Micrathena sp. (Araneae, Araneidae). Journal of Arachnology 38:371-373.

Nielsen, E. 1932. The Biology of Spiders. Levin \& Munkgaard, Copenhagen
Opell, B.D. 1989. Do female Miagrammopes animotus (Araneae, Uloboridae) spin color-coordinated egg sacs? Journal of Arachnology $17: 108-111$.

Théry, M. 2006. Effects of light environment on color communication. Pp. 148-173. In Bird Coloration, Mechanisms and Measurements. (G.E. Hill \& K.J. McGraw, eds.). Harvard University Press, Cambridge, Massachusetts.

Triana, E., G. Barrantes \& P. Hanson. 2012. Incidence of parasitoids and predators on eggs of seven Theridiidae species (Araneae). Bulletin of the British Arachnological Society 15:293-298.

Manuscript received 20 December 2012, revised 24 June 2013. 